\title{
FORMULASI ORALLY DISINTEGRATING TABLET (ODT) EKSTRAK ETANOL DAUN TAHONGAI (Kleinhovia hospita L.) DENGAN VARIASI KONSENTRASI EXPLOTAB ${ }^{\circledR}$
}

\author{
Formulation Of Orally Disintegrating Tablets (Odt) Of Tahongai Ethanol Extracts \\ (Kleinhovia Hospita L.) With Explotab® Concentration Variations
}

\author{
Hayatus Sa`adah, Reni Anggraini, Sapri \\ STIKES Samarinda \\ e-mail : hayatus.akfarsam@gmail.com
}

\begin{abstract}
Tahongai leaves (Kleinhovia hospita L.) is a medicinal plant that has antioxidant activity which is almost equivalent to vitamin $C$. The development of the dosage form to improve the utilization of these plants. Therefore Tahongai leaves made in the form Orally Disintegrating Tablets (ODT), which has several advantages such as more practical use because it can be consumed without the use of water and can be used by people who are hard to swallow capsules or tablets as well as having good taste in the mouth. This study was carried out experimentally using four formulas with various concentrations Explotab® ie; formula 1 (2\%); formula 2 (4\%); Formula 3 (6\%) and the formula 4 (8\%). The evaluation of ODT are uniformity of weight, hardness, friability and disintegration time.The results showed that the concentration Explotab® influence on the physical properties of ODT ie hardness, friability and disintegration time. Explotab ${ }^{B}$ concentration of $4 \%$ is the best concentration that meets the requirements of the physical properties ODT Tahongai leaf extract.
\end{abstract}

Keywords: Formulation, Orally Disintegrating Tablets (ODT), Explotab, Tahongai (Kleinhovia hospita L.)

\begin{abstract}
ABSTRAK
Daun Tahongai (Kleinhovia hospita L.) merupakan tanaman obat yang memiliki aktivitas antioksidan yang hampir setara dengan vitamin C. Perlu adanya pengembangan terhadap bentuk sediaan untuk meningkatkan pemanfaatan tanaman tersebut menjadi sediaan yang mudah dalam penggunaan. Oleh karena itu daun Tahongai dibuat dalam bentuk Orally Disintegrating Tablet (ODT) yang memiliki beberapa keuntungan diantaranya lebih praktis digunakan karena dapat dikonsumsi tanpa menggunakan air dan dapat digunakan oleh orang yang sukar menelan kapsul atau tablet serta memiliki rasa yang enak di mulut. Penelitian ini dilakukan secara eksperimental menggunakan empat formula dengan variasi konsentrasi Explotab ${ }^{\circledR}$ yaitu formula $1(2 \%)$; formula $2(4 \%)$; formula $3(6 \%)$ dan formula $4(8 \%)$. Selanjutnya dilakukan evaluasi sediaan ODT meliputi keseragaman bobot, kekerasan, kerapuhan dan waktu hancur. Hasil penelitian menunjukkan bahwa konsentrasi Explotab $^{\circledR}$ memberikan pengaruh terhadap sifat fisik ODT yaitu kekerasan, kerapuhan dan waktu hancur. Konsentrasi Explotab ${ }^{\circledR} \%$ merupakan konsentrasi terbaik yang paling mendekati persyaratan sifat fisik ODT ekstrak daun Tahongai.
\end{abstract}

Kata Kunci: Formulasi, Orally Disintegrating Tablet (ODT), Explotab, Tahongai 


\section{PENDAHULUAN}

Tahongai merupakan salah satu tanaman yang memiliki potensi sebagai tanaman obat. Di Indonesia daun Tahongai digunakan secara tradisional untuk menyembuhkan penyakit hati oleh beberapa suku seperti Toraja, Bugis dan Makassar. Senyawa yang terdapat di dalam ekstrak metanol daun Tahongai yang berpotensi memiliki aktivitas antioksidan adalah kaempferol3OBD-glukosida daneleutherol. Sebanyak $100 \mu \mathrm{g} / \mathrm{mL}$ ekstrak metanol daun Tahongai mempunyai aktivitas antioksidan sebesar $96 \%$ yang hampir sama dengan vitamin $\mathrm{C}$ yaitu sebesar $98 \%$ [1].

Saat ini telah terdapat 2 jenis sediaan daun Tahongai yaitu kapsul ekstrak daun Tahongai dan sediaan teh celup. Namun dari kedua sediaan tersebut masih terdapat beberapa kekurangan yaitu kapsul tidak cocok digunakan untuk orang yang sukar menelan kapsul dan dibutuhkan air untuk menelan kapsul. Sedangkan kekurangan dari teh celup adalah cara penggunaannya yang kurang praktis karena harus diseduh terlebih dahulu menggunakan air sebelum dikonsumsi.

Orally Disintegrating Tablet (ODT) atau Fast Release Tablet adalah sediaan padat yang hancur secara cepat dalam mulut dan residunya mudah ditelan. ODT mempunyai karakteristik waktu disintegrasi umumnya kurang dari 1 menit serta memiliki rasa yang enak [2\&3].Keuntungan dari ODT antara lain dapat digunakan pada orang tua yang sukar menelan dan tidak dapat diberikan bentuk sediaan oral konvensional (larutan, suspensi, tablet dan kapsul), anak-anak yang belum dapat menelan sediaan tablet atau kapsul, orang sakit dan pasien yang tidak mampu menelan untuk menghindari pemberian cairan serta pada orang yang mual [4]. Beberapa eksipien yang digunakan dalam pembuatan ODT antara lain disintegran, pengaroma, pemanis, pewarna, pengikat, dan pengisi [5].

Explotab $^{\circledR}$ merupakan disintegran yang bekerja dengan cepat menyerap air dan mengembang dalam air sebesar 200-300\% mengakibatkan hidrofilisitas dan pengembangan serta hancur dengan cepat. Explotab ${ }^{\circledR}$ digunakan sebagai superdisintegran dalam formulasi tablet pada konsentrasi 4-6\%. Di atas $8 \%$ mungkin waktu hancurnya benarbenar meningkat [6].Berdasarkan hal tersebut, dilakukan penelitian tentang formulasi ODT ekstrak daun Tahongai dengan variasi konsentrasi Explotab $^{\circledR}$ yang bertujuan untuk mengetahui konsentrasi terbaik Explotab $^{\circledR} \quad$ sebagai bahan penghancur ODT.

\section{METODE PENELITIAN}

\section{Alat dan Bahan}

Alat yang digunakan pada penelitian ini diantaranya: blender, maserator, flowability tester, disintegration tester, friabilator, hardness tester, pencetak tablet single punch, pengayak mesh 14, 20 dan 100, stamper, stopwatch.

Bahan yang digunakan pada penelitian ini adalah aerosil (kualitas farmasetis), aspartam (kualitas farmasetis), aquades (kualitas farmasetis), daun Tahongai, etanol $70 \%$, Explotab ${ }^{\circledR}$ (kualitas farmasetis), gelatin (kualitas farmasetis), magnesium stearat (kualitas farmasetis), manitol (kualitas farmasetis), talk (kualitas farmasetis). 


\section{PROSEDUR PENELITIAN Ekstraksi Daun Tahongai}

Ekstraksi daun tahongai dilakukan dengan metode maserasimenggunakan pelarut etanol $70 \%$ Remaserasi dilakukan sebanyak 3 kali.Ekstrak cair yang diperoleh pada proses ekstraksi dipanaskan sampai diperoleh ekstrak kental yang dalam keadaan dingin tidak dapat dituang.

Pembuatan ODT dengan Metode Granulasi Basah.

Bahan ditimbang sesuai dengan formula pada tabel 1.Ekstrak kental daun Tahongai ditambahkan aerosil sedikit demi sedikit sambil diaduk sampai homogen. Manitol, aspartam dan Explotab ${ }^{\circledR}$ ditambahkan, diaduk sampai homogen.Gelatin dipanaskan dengan $14 \mathrm{~mL}$ aquades sampai gelatin larut seluruhnya. Larutan gelatin ditambahkan sedikit demi sedikit ke dalam campuran bahan, diaduk sampai terbentuk massa yang baik. Massa yang terbentuk diayak dengan pengayak mesh 14. Granul basah dikeringkan dalam oven pada suhu $50-60^{\circ} \mathrm{C}$ selama 2 jam. Granul kering diayak dengan pengayak mesh 20 dan ditambahkan aerosil, magnesium stearat serta talk, dicampur sampai homogen.

Dilakukan evaluasi granul yang meliputi evaluasi waktu alir, sudut diam, pengetapan, densitas massa dan kadar lembab. Granul dicetak dan dilakukan evaluasi tablet meliputi evaluasi keseragaman bobot, kekerasan, kerapuhan dan waktu hancur tablet.

Tabel 1. Formula ODT Ekstrak Etanol Daun Tahongai

\begin{tabular}{|c|c|c|c|c|}
\hline \multirow{2}{*}{ Bahan } & \multicolumn{4}{|c|}{ Formula(mg/tablet) } \\
\hline & I & II & III & IV \\
\hline Ekstrak Daun Tahongai & 50 & 50 & 50 & 50 \\
\hline Aerosil untuk ekstrak & 10 & 10 & 10 & 10 \\
\hline Explotab® & 8 & 16 & 24 & 32 \\
\hline Aspartam & 4 & 4 & 4 & 4 \\
\hline Magnesium Stearat & 10 & 10 & 10 & 10 \\
\hline Aerosil & 2 & 2 & 2 & 2 \\
\hline Talk & 10 & 10 & 10 & 10 \\
\hline Gelatin & 4 & 4 & 4 & 4 \\
\hline Manitol & 302 & 294 & 286 & 278 \\
\hline
\end{tabular}

\section{HASIL DAN PEMBAHASAN}

Metode pembuatan tablet yang digunakan pada penelitian ini adalah metode granulasi basah. Hasil penelitian (tabel 2) menunjukkan bahwa semua formula memiliki waktu alir dan kecepatan alir yang memenuhi persyaratan yaitu kecepatan alirnya lebih dari 10 g/detik[7]. 


\section{JFL \\ Jurnal Farmasi Lampung \\ Vol. 8. No. 1 Juni 2019}

Tabel 2. Data Waktu Alir, Kecepatan Alir, Sudut Diam, Pengetapan, Densitas Massa Dan Kadar Lembab Granul

\begin{tabular}{c|c|c|c|c|c}
\hline Formula & $\begin{array}{c}\text { Kecepatan } \\
\text { Alir (g/detik) }\end{array}$ & $\begin{array}{c}\text { Sudut } \\
\text { Diam ( }\end{array}$ & $\begin{array}{c}\text { Pengetapan } \\
(\%)\end{array}$ & $\begin{array}{c}\text { Densitas } \\
\text { Massa } \\
(\mathbf{g} / \mathbf{m L})\end{array}$ & $\begin{array}{c}\text { Kadar } \\
\text { Lembab } \\
(\%)\end{array}$ \\
\hline I & 12,5 & 30,92 & 2 & 0,43 & 3,2 \\
\hline II & 12,5 & 33,14 & 2,86 & 0,46 & 3 \\
\hline III & 12,5 & 32,20 & 5,71 & 0,48 & 2,2 \\
\hline IV & 12,5 & 33,14 & 3,81 & 0,46 & 2 \\
\hline
\end{tabular}

Keterangan:

Formula I = Explotab ${ }^{\circledR} 2 \%$

Formula II = Explotab ${ }^{\circledR} 4 \%$

Formula III = Explotab $^{\circledR} 6 \%$

Formula IV = Explotab ${ }^{\circledR} 8 \%$

Berdasarkan hasil penelitian menunjukkan bahwa semua formula memiliki sudut diam yang memenuhi persyaratan yaitu antara $30-40^{\circ}$. Namun jika dibandingkan semua formula maka formula I memiliki sudut diam paling kecil. Sudut diam sangat dipengaruhi oleh waktu alir, apabila waktu alirnya cepat maka sudut diam yang dihasilkan kecil dan sebaliknya jika waktu alirnya lambat maka sudut diamnya akan besar [8].

Indeks pengetapan erat kaitannya dengan kemampuan serbuk untuk dimampatkan (dikempa) [9]. Formula III memiliki indeks pengetapan paling besar dibandingkan dengan formula lainnya, hal ini mungkin disebabkan banyaknya fines pada formula tersebut. Fines yang banyak dapat disebabkan oleh proses granulasi yang kurang sempurna atau karena pengaruh tekanan yang terlalu besar pada saat pengayakan granul [10].

Pengukuran densitas massa bertujuan untuk menentukan ruang kosong antar partikel pada granul. Formula I memiliki densitas massa paling kecil sedangkan formula III memiliki densitas massa paling besar. Adanya perbedaan densitas massa diduga disebabkan oleh perbedaan ukuran partikel granul sehingga fines mengisi ruang kosong antar partikel pada granul. Hal ini yang menyebabkan nilai densitas massa meningkat.

Persyaratan kadar lembab granul yaitu 2-5 \% [11]. Semua formula pada penelitian ini memenuhi persyaratan kadar lembab granul. Hal ini menunjukkan bahwa penggunaan adsorben cukup mengurangi kadar lembab pada granul. Kadar lembab granul dapat dipengaruhi oleh kadar air dalam ekstrak, banyaknya larutan pengikat, kondisi kelembaban dan lamanya pengeringan granul.

Berdasar uji yang telah dilakukan dapat disimpulkan bahwa semua formula memenuhi persyaratan sifat fisik granul yang baik atau variasi konsentrasi Explotab $^{\circledR}$ tidak mempengaruhi kualitas granul yang dihasilkan. 


\section{Evaluasi Tablet ODT Ekstrak Daun tahongai}

Granul yang sudah dievaluasi kemudian dicetak menjadi tablet. Evaluasi tablet meliputi keseragaman bobot, kekerasan, kerapuhan dan waktu hancur.

Tabel 3. Hasil Uji Sifat Fisik Tablet

\begin{tabular}{|c|c|c|c|c|c|}
\hline \multirow{2}{*}{ Formula } & \multicolumn{2}{|c|}{ Keseragaman bobot } & \multirow{2}{*}{$\begin{array}{c}\text { Kekerasan } \\
\left(\mathrm{Kg} / \mathrm{cm}^{2}\right)\end{array}$} & \multirow{2}{*}{$\begin{array}{c}\text { Kerapuhan } \\
\text { (\%) }\end{array}$} & \multirow{2}{*}{$\begin{array}{l}\text { Waktu } \\
\text { hancur } \\
\text { (detik) }\end{array}$} \\
\hline & $\begin{array}{c}\text { Bobot } \\
\text { rata-rata }(\mathrm{mg})\end{array}$ & $\begin{array}{l}\text { Koefisien } \\
\text { variasi (\%) }\end{array}$ & & & \\
\hline $\mathrm{I}$ & $355 \pm 0,007$ & 0,002 & 2,43 & 0,30 & 112 \\
\hline II & $362 \pm 0.018$ & 0,005 & 2,41 & 4,89 & 53 \\
\hline III & $372 \pm 0,016$ & 0,004 & 1,45 & 15,31 & 47 \\
\hline IV & $369 \pm 0,008$ & 0,002 & 1,47 & 0,55 & 188 \\
\hline \multicolumn{6}{|c|}{$\begin{array}{l}\text { Keterangan: } \\
\text { Formula I = Explotab }{ }^{\circledR} 2 \% \\
\text { Formula II = } \text { Explotab }^{\circledR} 4 \% \\
\text { Formula III }=\text { Explotab }^{\circledR} 6 \% \\
\text { Formula IV }=\text { Explotab }^{\circledR} 8 \%\end{array}$} \\
\hline
\end{tabular}

Keseragaman bobot dipengaruhi oleh sifat alir dari granul. Keseragaman bobot juga dipengaruhi oleh ukuran granul dan jumlah fines. Selain itu, tekanan pada bahan yang diisikan juga dapat mempengaruhi keseragaman bobot. Pada penelitian ini, formula I memiliki standar deviasi dan koefisien variasi paling kecil, hal ini disebabkan waktu alir yang dimiliki formula I paling baik.

Uji kekerasan tablet dilakukan untuk mengetahui kekerasan tablet. Hasil penelitian menunjukkan bahwa terjadi penurunan kekerasan tablet dengan adanya peningkatan konsentrasi $\quad$ Explotab $^{\circledR}$.Syarat kekerasan ODT adalah 1-3 $\mathrm{kg} / \mathrm{cm}^{2}$ [12]. Berdasarkan hal tersebut maka disimpulkan bahwa semua formula memenuhi syarat kekersan ODT.
Penggunaan Explotab ${ }^{\circledR}$ memberikan pengaruh pada kerapuhan tablet, semakin besar konsentrasi Explotab $^{\circledR}$ semakin rapuh tablet yang dihasilkan. Persyaratan kerapuhan ODT yaitu di antara $0,1 \%$ - 0,9\% [13]. Hasil uji menunjukkan bahwa hanya formula I yang memenuhi syarat kerapuhan ODT.

Explotab $^{\circledR}$ mempengaruhi waktu hancur tabletdengan menarik air ke dalam tablet kemudian mengembang dan menyebabkan tablet pecah. Hasil penelitian menunjukkan bahwa semakin tinggi konsentrasi Explotab $^{\circledR}$ semakin berkurang waktu hancurnya atau tablet hancur semakin cepat. Namun pada konsentrasi yang dinaikkan sampai $8 \%$ waktu hancurnya justru makin lambat. Hal ini kemunggkinan karena konsentrasi Explotab ${ }^{\circledR}$ telah mengalami kejenuhan. 
Orally Disintegrating Tablet diformulasikan dengan suatu disintegran yang akan menyebabkan tablet pecah dan hancur di mulut ketika kontak dengan air ludah/saliva dalam waktu kurang dari 60 detik [14]. Berdasar hal tersebut menunjukkan bahwa hanya formula II dan III yang memenuhi syarat waktu hancur ODT

Berdasarkan hasil-hasil pengujian tersebut menunjukkan bahwa tidak ada formula ODT ekstrak daun Tahongai yang memenuhi semua persyaratan fisik ODT, namun jika dibandingkan semua formula maka formula yang terbaik adalah formula II dengan konsentrasi Explotab ${ }^{\circledR} \%$.

\section{KESIMPULAN}

Berdasarkan hasil penelitian yang dilakukan untuk mengetahui konsentrasi terbaik Explotab $^{\circledR}$ sebagai bahan penghancur ODT dapat disimpulkan bahwa konsentrasi $\quad$ Explotab $^{\circledR} \quad 4 \%$ merupakan konsentrasi terbaik yang paling mendekati persyaratan sifat fisik ODT ekstrak daun Tahongai.

\section{DAFTAR PUSTAKA}

[1] Arung E.T., Kusuma I.W., Purwatiningsih S., Roh S.S., Yang C.H., Jeon S., Kim Y.U., Sukaton E., Susilo S., Astuti A., Wicaksono B.D., Sandra F., Shimizu K., Kondo R. 2009. Antioxidant Activity and Cytotoxicity of The Traditional Indonesian Medicine Tahongai (Kleinhovia hospita L.) Extract. J Acupunct Meridian Stud. (4): 306-308.
[2] Dobetti L. 2001. Fast Melting Tablets: Developments and Technologies. J. Pharm. Tech: 44-48.

[3] Klancke J. 2003. Dissolution Testing of Orally Disintegrating Tablets. J. Diss. Tech: 6-8.

[4] Chang R., Guo X., Burnside B.A., Couch R. 2000. Fast Dissolving Tablets. J. Pharm. Tech. 24. (6): 52-58.

[5] Liang, A.C. dan L.I.H. Chen. 2001. Fast-Dissolving Intraoral Drug Delivery Systems. Expert Opinion on Therapeutic Patents. (6): 981-986.

[6] Sharma D. 2013. Formulation Development and Evaluation of Fast Disintegrating Tablets of Salbutamol Sulphate for Respiratory Disorders. J. ISRN Pharmaceutics.

[7] Fudholi, A., 1983, Metodologi Formulasi Dalam Kompresi Direk, Medika, 7(9), 586-593.

[8] Nurwaini S. dan Erindyah R.W. 2011. Formulasi Tablet Hisap Ekstrak Daun Kemangi (Ocimum sanctum L.): Jurnal Penelitian Sains \& Teknologi.(1): 45-57

[9] Windriyati Y.N. dan Sugiono. 2014. Formulasi Tablet Hisap Ekstrak Daun Sirih Merah (Piper crocotum Ruiz dan Par), dengan Variasi Pemanis. Farmasains. 2. (4).

[10] Atmajasari D. 2014. Formulasi Tablet Hisap Kombinasi Ekstrak Air Kulit Buah Manggis (Garcinia mangostana L.) dan Ekstrak Air Kelopak Bunga Rosella (Hibiscus sabdariffa L.) 
Menggunakan Gelatin sebagai Bahan Pengikat. Skripsi. Jakarta: UIN Syarif Hidayatullah.

[11] Saifullah T.N. 2007. Teknologi dan Formulasi Sediaan Tablet. Yogyakarta : Pustaka Laboratorium Teknologi Farmasi Fakultas Farmasi Universitas Gadjah Mada.

[12] Izza, Khawla A.A., Li, Vincent H., Look, Jee L., Parr, Graham D., dan Schineller, Matthew K. 2009. Fast Dissolving Tablet. Dalam : Bhupendra G Prajapati and Nayan Ratnakar. A Review on Recent Patents on Fast Dissolving Drug Delivery
System. Int. J. Pharm. Tech. Research.

[13] Dhadve,Avinash. K dan Chander. P. Rathod. 2013. Formulation and Evaluation of Orodispersible Tablet (ODT) of Cinnarizine by Direct Compression Method: A Review. Indo American Journal of Pharmaceutical Research.

[14] Kundu, S. dan P.K. Sahoo. 2008. Recent Trends in The Developments of Orally Disintegrating Tablet Technology. Pharma Times. 